\title{
Perencanaan Enterprise Architecture Sistem Pelayanan Menggunakan Metode TOGAF (Studi Kasus : BPJS Kesehatan Cabang Kendal)
}

\author{
Marini $^{1}$, Yupie Kusumawati ${ }^{2}$, Florentina Esti Nilawati ${ }^{3}$ \\ Fakultas Ilmu Komputer, Universitas Dian Nuswantoro Semarang \\ e-mail: ${ }^{1}$ marinirini383@gmail.com, ${ }^{2}$ yupie@dsn.dinus.ac.id, \\ ${ }^{3}$ florentina.esti.nilawati@dsn.dinus.ac.id
}

Diterima: 27 April 2020; Direvisi: 23 Nopember 2020; Disetujui: 24 Nopember 2020

\begin{abstract}
Abstrak
BPJS Kesehatan selama ini belum memanfaatkan teknologi informasi secara maksimal dalam mendukung proses bisnisnya. Proses bisnis yang belum dilakukkan secara optimal antara lain proses pendaftaran bayi baru lahir, proses konfirmasi kepesertaan dan proses cetak kartu sementara bayi baru lahir. Hal ini disebabkan karena masih ada ketidaksamaan antara arsitektur bisnis, arsitektur sistem informasi dan arsitekture teknologi informasi.Permasalahan tersebut mengakibatkan pelayanan terhadap peserta BPJS Kesehatan tidak efisien. Adapun tujuan yang akan dicapai yaitu menghasilkan blueprint enterprise architecture Sistem Pelayanan BPJS Kesehatan berbasis web dengan framework TOGAF. Penelitian ini menggunakan kerangka kerja TOGAF dengan metode ADM (Architecture Development Method) berdasarkan data kualitatif yang didapat dari hasil wawancara. Hasil akhir dari penelitian ini berupa blueprint enterprise architecture yang diharapkan dapat mempermudah dan mengintegrasikan proses bisnis pelayanan pada BPJS Kesehatan Cabang Kendal.
\end{abstract}

Kata kunci: TOGAF, Enterprise Architecture, Blueprint, Sistem Pelayanan BPJS Kesehatan, Ptototype System

\begin{abstract}
BPJS Kesehatan has not utilized information technology to the fullest in supporting its business processes. Business processes that have not been optimally implemented include the process of registering a new baby, the process of confirmation of membership and the process of printing cards while a newborn is born. This is because there are still differences between business architecture, information system architecture and information technology architecture. These problems result in inefficient service for BPJS Health participants. The goal to be achieved is to produce a web-based enterprise architecture blueprint BPJS Health Service System with the TOGAF framework. This study uses the TOGAF framework with the ADM (Architecture Development Method) method based on qualitative data obtained from interviews. The final results of this research are in the form of a blueprint enterprise architecture that is expected to simplify and integrate service business processes at BPJS Kesehatan Kendal Branch.
\end{abstract}

Keywords: TOGAF, Enterprise Architecture, Blueprint, Sistem Pelayanan BPJS Kesehatan, Ptototype System 


\section{PENDAHULUAN}

Pada masa kini, kesehatan marupakan hal terpenting bagi semua orang, dengan keadaan sehat maka individu dapat melakukkan aktifitas sehari-hari dengan produktif. Kesehatan banyak menimbulkan kekhawatiran yang berlebihan disebabkan karena berbagai macam penyakit yang dapat merusak kondisi tubuh sama seperti halnya yang terjadi di Indonesia sekarang ini. Untuk pelayanan kesehatan bagi masyarakat yang kurang mampu yang tinggal di perkotaan dan juga pedesaan masih sulit untuk mendapatkan pelayanan kesehatan yang maksimal. Faktor penyebab utama dari masalah finansial dan faktor penyebab lainnya dari sumber daya manusia yang relatif rendah disebabkan karena keterbatasan informasi tentang aturan hak dan kewajiban masyarakat sebagai pasien yang membutuhkan pelayanan medis. Agar dapat terhindar dari hal yang tidak diinginkan, seperti pelayanan yang kurang adil untuk masyarakat mampu dan tidak mampu terutama dari tenaga medis itu sendiri yang kurang menyenangkan, malpraktik dan lainnya maka pemerintah mengharapkan semua rakyat dapat meperoleh pelayanan yang sama [1].

Pemerintah berusaha memberikan pelayanan kesehatan dengan cara membentuk suatu badan hukum publik yaitu BPJS Kesehatan dahulu bermana Askes (Asuransi Kesehatan) yang diresmikan pada tanggal 31 Desember 2013 dan mulai beroprasi sejak tanggal 1 Januari 2014 [2]. Tugas dari BPJS Kesehatan untuk menyelenggarakan program jaminan kesehatan bagi seluruh rakyat agar dapat memenuhi kebutuhan dasar hidupnya yang memandai.BPJS Kesehatan sebagai koordinator yang bekerjasama dengan fasilitas kesehatan untuk mendukung menyelenggarakan program jaminan kesehatan secara merata bagi masyarakat.Jaminan kesehatan BPJS Kesehatan untuk setiap orang, termasuk orang asing yang bekerja paling singkat enam bulan di Indonesia, yang telah membayar iuran. Kepesertaan BPJS Kesehatan terdiri dari 3 jenis : peserta yang terdaftar melalui program bantuan pemerintah (PBI), peserta terdaftar melalui perusahaan tempat bekerja (PPU), dan peserta yang terdaftar secara mandiri (PBPU).

BPJS Kesehatan telah memiliki 2 (dua) jenis aplikasi pelayanan yang pertama adalah BPJS berbasis web atau aplikasi kepesertaan BPJS yang hanya digunakan untuk support proses seperti pendaftaran anggota, pencetakan kartu, pendaftaran yang belum dilakukkan secara konvensional. Aplikasi kedua adalah BPJS berbasis mobile atau JKN Mobile yang dapat dimanfaatkan peserta BPJS untuk pendaftaran peserta selain bayi baru lahir, edit data peserta, layanan tagihan dan layanan informasi umum.

Walaupun BPJS memiliki 2 aplikasi namun berdasarkan hasil wawancara dengan pimpinan kantor cabang BPJS masih terdapat kekurangan dari sistem tersebut. Kekurangannya adalah dari aplikasi berbasis web tidak dapat update data pendaftran secara real time. Sedangkan dari aplikasi berbasis mobile kekurangannya adalah tidak adanya menu pendaftaran bayi baru lahir, tidak ada konfirmasi kepesertaan yang akan mengakibatkan muncul tagihan secara terus menerus dan tidak ada menu cetak kartu pendaftaran bayi baru lahir.

Permasalahan yang terjadi selama ini disebabkan karena sistem yang berjalan di BPJS Kesehatan memiliki ketidaksesuaian antara arsitektur bisnis, arsitektur sistem informasi dan arsitektur teknologi informasi sehingga perlu dilakukkan usulan perancangan enterprise arsitektur sistem pelayanan yang ada pada BPJS Kesehatan yang akan menghasilkan blue print enterprise arsitektur sistem informasi pelayanan BPJS Kesehatan berbasis web. Untuk merancang enterprise architecture sistem informasi pelayanan diperlukan kerangka kerja (framework) [3]. Dalam perusahaan maupun organisasi sering menggunakan The Open Group Architecture Framework (TOGAF) dan The Zahman Framework for Enterprise Architecture [4]. TOGAF memberikan suatu framework arsitektur yang tepat untuk mengembangkan desain, perancangan secara detail, implementasi serta mengontrol sebuah arsitektur suatu perusahaan maupun organisasi melalui Architecture Enterprise Method (ADM). Sedangkan framework Zahman memberikan prinsip-prinsip architecture klasik yang membentuk persamaan umum, karena kinerja ini tidak memberikan panduan seperti pada TOGAF yang memiliki Architecture Enterprise Method (ADM) yang menyediakan prosedur terstruktur untuk merancang suatu 
arsitektur secara menyeluruh [5]. Fase TOGAF tidak harus lengkap dapat dirancang sesuai dengan situasi kebutuhan yang ada dan bersifat fleksibel mengenai perancangan arsitektur.

\section{METODE PENELITIAN}

Metodologi pengumpulan data yang digunakan pada penelitian ini antara lain wawancara, observasi dan studi kasus pada BPJS Kesehatan Cabang Kendal. Sedangkan metode analisis yang digunakan terdapat 10 tahap pada TOGAF[6] sesuai pada gambar 1 berikut:

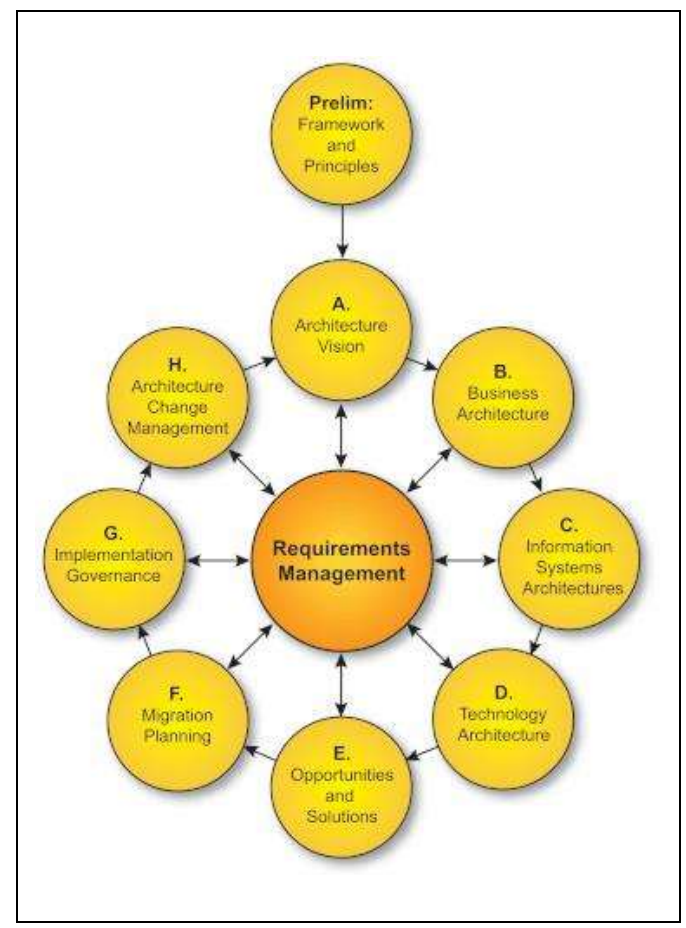

Gambar 1. Metode analisis

1. Fase preliminary

Fase preliminary ini tentang menjelaskan bagaimana melakukkan perancangan di BPJS Kesehatan. Pada fase ini akan dilakukkan tahap mengidentifikasi 5W (What, Who, Where, Why dan When) $+1 \mathrm{H}$ (how) dalam arsitektur. Tool yang digunakan principles catalog.

2. Requirement Management

Fase ini bertujuan melakukkan analisa kebutuhan dari BPJS Kesehatan.dengan menggunakan Tool Rich Picture. Dengan mengidentifikasi permasalahan pada BPJS Kesehatan. Membuat solusi aktifitas dari masalah yang telah diidentifikasi. Membuat solusi pengembangan sistem dari permasalahan yang telah diidentifikasi.

3. Phase A : Architecture Vision

Fase architecture ini mempunyai tujuan menciptakan keseragaman cara pandang mengenai pentingnya enterprise architecture untuk mencapai tujuan dari organisasi yang dirumuskan dalam bentuk strategi, dan menentukan lingkup dari arsitektur yang akan dikembangkan. Penulis menguraikan beberapa tahapan untuk menentukan visi arsitektur berdasarkan pada objek penelitian dengan menentukan dan mengidentifikasi visi BPJS Kesehatan serta menetukan aktifitas proses kerja pada BPJS Kesehatan. 


\section{Phase B : Business Architecture}

Fase ini bertujuan menjelaskan model aktivitas seperti sejarah perusahaan, proses, dan fungsi yang digunakan untuk menentukan BPJS Kesehatan pada masa yanga akan mendatang melalui sudut pandang dari organisasi tersebut. Langkah-langkah untuk membangun arsitektur bisnis yaitu menjelaskan sejarah BPJS Kesehatan, struktur organisasi BPJS Kesehatan beserta deskripsi dan membuat rancangan arsitektur aktivitas di BPJS Kesehatan.

\section{Phase $C$ : Information System Architecture}

Pada aktivitas ini membahas bagaimana membangun suatu sistem informasi arsitektur yang dikembangkan di BPJS Kesehatan, meliputi arsitektur aplikasi dan arsitektur data. Beberapa tahapannya dengan mengidentifikasi aplikasi-aplikasi yang dibutuhkan, membuat pemodelan aplikasi-aplikasi yang akan dibuat, mengidentifikasi struktur data yang diperlukan pada setiap aplikasi dan membuat permodelan arsitektur data.

6. Phase D : Technology Information

Fase ini akan menggambarkan perancangan arsitektur teknologi-teknologi utama yang dibutuhkan, untuk mendukung sistem informasi yang akan diperlukan pengembangan sistem di BPJS Kesehatan. Adapun dengan membuat konfigurasi jaringan usulan dan menentukan software dan hardware yang diperlukan.

\section{Phase E : Opportunities and Solution}

Fase ini akan diuraikan dari hasil analisis fase arsitektur bisnis sampai arsitektur teknologi dengan cara melakukan evaluasi terhadap model yang sudah dibangun untuk semua arsitektur (Bisnis, Aplikasi, Data, dan Teknologi). Serta mengidentifikasi keterkaitan hubungan arsitektur data dan antar aplikasi.

Tool yang digunakan Matrix Analysis Gap.

8. Phase F : Migration Planning

Pada fase ini akan dilakukan persiapan dan perancangan migrasi untuk implementasi arsitektur baru yang dibangun pada fase sebelumnya dengan melakukkan penyusunan urutan proyek-proyek berdasarkan prioritas pengimplementasian aplikasi serta menetapkan dan menggambarkan roadmap aplikasi pada BPJS Kesehatan.

9. Phase $G$ : Implementation Governance

Proyek yang dilaksanakan yaitu sebagai program rencana kerja agar dapat mencapai arsitektur yang diinginkan dengan melakukkan dalam penyusunan aplikasi dan pengawasan dalam implementasi arsitektur aplikasi.

\section{Phase H : Architecture Change Management}

Tahapan ini yaitu membahas usulan atau perubahan pada sistem sebelumnya yang sudah dirancang dan menetapkan arsitektur manajemen yang telah diimplementasi dengan menyediakan analisis untuk architecture change management dan mengaktifkan proses untuk penerapkan perubahan.

\section{HASIL DAN PEMBAHASAN}

Sumber bagian ini menjelaskan mengenai analisis yang dilakukkan pada BPJS Kesehatan serta perancangan enterprise architecture menggunakan framework TOGAF ADM dimulai preliminary phase, requirement management, architecture vision, business architecture, informasi system architecture, technologi information, opportunities and solution, migration planning, implementasi governance, sampai architecture change management. 


\subsection{Identifikasi Proses Bisnis Pada BPJS Kesehatan}

Berdasarkan analisis proses bisnis yang telah dilakukkan dapat digambarkan arsitektur proses seperti pada gambar 2 berikut :

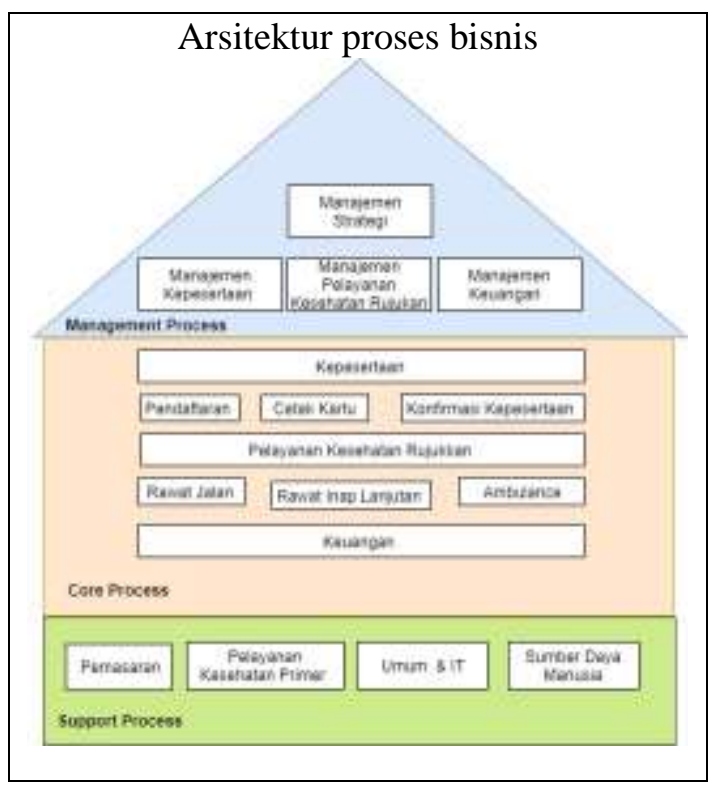

Gambar 2. Arsitektur Proses Bisnis BPJS Kesehatan

\subsection{Preliminary Phase}

Preliminary Phase merupakan tahap awal dalam persiapan perancangan enterprise architecture. Tahap ini menentukan bagaimana enterprise architectureakan dibuat dan berjalan dengan baik. Berikut prinsip-prisip yang akan dipakai oleh BPJS Kesehatan Cabang Kendal serta penjelasan tujuan dari prinsip sebagai berikut :

1. Prinsip-prinsip perancangan Enterprise Architecture

Prinsip-prinsip perancangan enterprise architecture yang digunakan untuk menggambarkan karakteristik EA sistem informasi yang akan dikembangkan dalam pelayanan BPJS Kesehatan Kantor Cabang Kendal. Berikut pada tabel 1 Prinsip-prinsip yang akan digunakan.

Tabel 1. Prinsip-prinsip perancangan Enterprise Architecture

\begin{tabular}{|c|c|}
\hline No & Prinsip \\
\hline 1. & $\begin{array}{l}\text { Keputusan arsitektur yang } \\
\text { dibuat harus mengacu pada } \\
\text { tujuan, aktivitas, serta proses } \\
\text { bisnis di BPJS Kesehatan } \\
\text { Kantor Cabang Kendal. }\end{array}$ \\
\hline 2. & $\begin{array}{l}\text { Prinsip yang telah dibuat } \\
\text { harus bisa diterapkan pada } \\
\text { setiap bagian BPJS Cabang } \\
\text { Kendal }\end{array}$ \\
\hline 3. & $\begin{array}{l}\text { Pengelolaan arsitektur yang } \\
\text { dikembangkan harus dengan } \\
\text { mudah sehingga dapat } \\
\text { membantu kerjasama dengan } \\
\text { baik antar devisi pada BPJS }\end{array}$ \\
\hline
\end{tabular}

a. Mendukung aktivitas dan proses bisnis di BPJS Kesehatan Kantor Cabang Kendal.

b. Meningkatkan pelayanan untuk peserta dan masyarakat.

a. Mendukung suatu proses bisnis yang ada pada BPJS Kesehatan terutama pada bagian pelayanan peserta.

a. Meningkatkan mutu pelayanan yang baik di BPJS Kesehatan Cabang Kendal. 


\begin{tabular}{|c|c|c|}
\hline No & Prinsip & Tujuan \\
\hline 4. & $\begin{array}{l}\text { Kesehatan Cabang Kendal } \\
\text { Pengelolaan data harus } \\
\text { dengan baik }\end{array}$ & $\begin{array}{l}\text { a. Memastikan tempat penyimpanan dari data } \\
\text { peserta yang ada dan ketelitian dengan data } \\
\text { berguna untuk menjaga keamanan dan juga } \\
\text { kerahasiaan data. } \\
\text { b. Pengaksesan yang dapat dilakukkan kapanpun } \\
\text { dan dimanapun untuk menjaga keamanan dan } \\
\text { kerahasiaan data dari orang yang tidak } \\
\text { berkepentingan. }\end{array}$ \\
\hline 5. & $\begin{array}{l}\text { Data dan informasi harus } \\
\text { saling terintegrasi antar devisi } \\
\text { pada BPJS Kesehatan Cabang } \\
\text { Kendal }\end{array}$ & $\begin{array}{l}\text { a. Memudahkan pemprosesan data peserta dan } \\
\text { informasi dalam meningkatkan kualitas } \\
\text { pelayanan yang baik pada BPJS Kesehatan. }\end{array}$ \\
\hline 6. & $\begin{array}{l}\text { Data harus dilindungi dari } \\
\text { penggunaan dan publikasi } \\
\text { yang tidak berijin. }\end{array}$ & $\begin{array}{l}\text { a. Untuk melindungi agar data dan informasi } \\
\text { terlindungi dari orang tidak berwenang } \\
\text { mengakses. } \\
\text { b. Memudahkan dalam pengaksesan data secara } \\
\text { cepat untuk meningkatkan pelayanan kepada } \\
\text { peserta serta pengambilan keputusan. }\end{array}$ \\
\hline 7. & $\begin{array}{l}\text { Data dan informasi harus } \\
\text { mudah diakses. }\end{array}$ & $\begin{array}{l}\text { a. Memudahkan dalam pengaksesan data secara } \\
\text { cepat untuk meningkatkan pelayanan pada } \\
\text { peserta serta pengambilan keputusan. }\end{array}$ \\
\hline 8. & $\begin{array}{l}\text { Pengoprasian aplikasi yang } \\
\text { ada untuk platform teknologi. }\end{array}$ & $\begin{array}{l}\text { a. Aplikasi dapat dikembangan dan juga dapat } \\
\text { dioprasikan dengan lebih efektif dan efisien. }\end{array}$ \\
\hline 9. & $\begin{array}{l}\text { Pembuatan aplikasi-aplikasi } \\
\text { dengan design yang mudah }\end{array}$ & $\begin{array}{l}\text { a. Mempermudah penggunaan user agar user dapat } \\
\text { berfokus pada tugas masing-masing }\end{array}$ \\
\hline 10. & $\begin{array}{l}\text { Pengembangan architecture } \\
\text { harus dirancang }\end{array}$ & $\begin{array}{l}\text { a. Memudahkan penambahan dan pengembangan } \\
\text { sistem pelayanan dimasa depan }\end{array}$ \\
\hline 11. & $\begin{array}{l}\text { Menggunakan software, } \\
\text { hardware dan platform yang } \\
\text { standar }\end{array}$ & $\begin{array}{l}\text { a. Mempermudah perancangan enterprise } \\
\text { architecture }\end{array}$ \\
\hline
\end{tabular}

\section{Identifikasi $5 \mathrm{~W}+1 \mathrm{H}$}

Setelah menentukan principles catalog, langkah selanjutnya yaitu mengidentifikasi objek dalam perancangan arsitektur untuk BPJS Kesehatan Kantor Cabang Kendal. Berikut pada tabel 2 rancangan arsitektur untuk BPJS Kesehatan Kantor Cabang Kendal :

Tabel 2. Identifikasi $5 \mathrm{~W}+1 \mathrm{H}$

\begin{tabular}{|c|c|}
\hline Drive & Deskripsi \\
\hline 1. What & $\begin{array}{l}\text { Objek : Menjelaskan data dan hubungan antar masing-masing data } \\
\text { tersebut. } \\
\text { Deskripsi : Data peserta dari pendaftaran, pembayaran, dan konfirmasi } \\
\text { kepesertaan }\end{array}$ \\
\hline 2. Who & $\begin{array}{l}\text { Objek : Peran BPJS Kesehatan Cabang Kendal dan unit dari hubungan } \\
\text { antar keduanya. } \\
\text { Deskripsi : } \\
\text { Stakeholder dan BPJS Kesehatan Cabang Kendal. }\end{array}$ \\
\hline 3. Where & $\begin{array}{l}\text { Objek : Lokasi penelitian } \\
\text { Deskripsi : BPJS Kesehatan, Jl.Pemuda No.21,Karanggeneng, } \\
\text { Pegulon, Kec.Kendal, Kabupaten Kendal, Jawa Tengah } 51318 .\end{array}$ \\
\hline
\end{tabular}




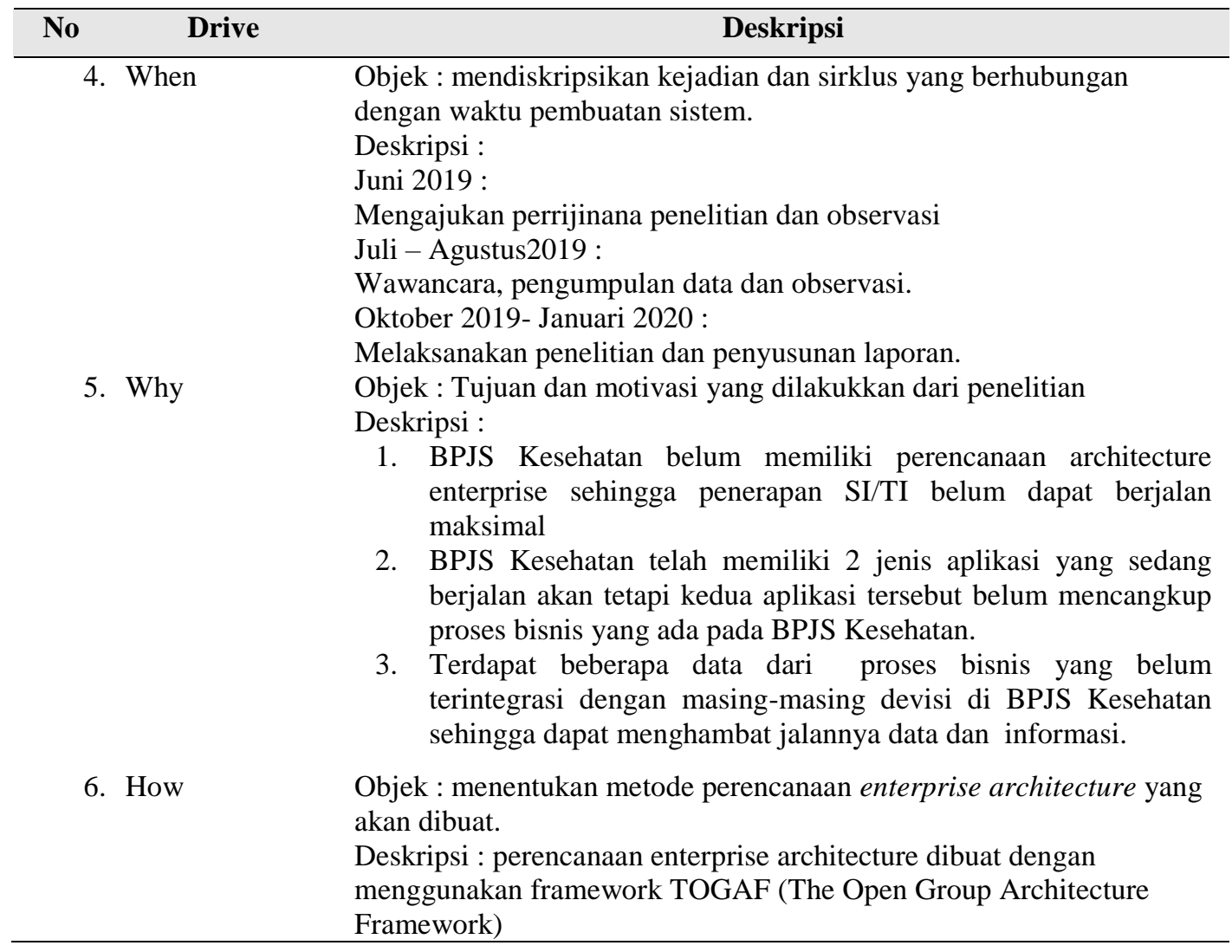

\subsection{Phase A : Architecture Vision}

Analisis value chain BPJS Kesehatan dapat dikelompokkan berdasarkan aktifitasaktifitas yang tampak pada gambar 3. Dapat terbagi dalam dua kelompok yaitu aktifitas utama dan aktifitas pendukung yang ada pada BPJS Kesehatan Cabang Kendal :

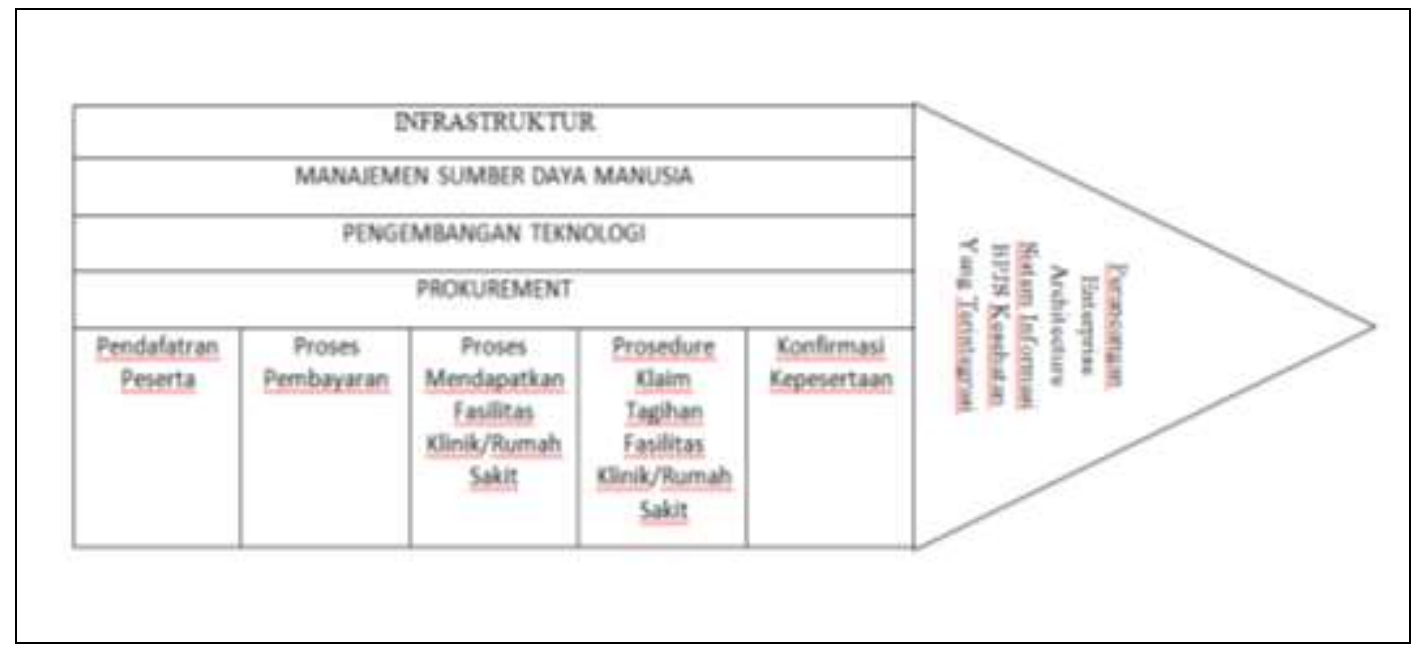

Gambar 3. Analisis Value Chain

\subsection{Phase B : Business Architecture}

1. Usulan sistem pendaftaran calon peserta pada BPJS Kesehatan Cabang Kendal

Usulan proses bisnis pelayanan pendaftaran dan cetak kartu sementara bayi baru lahir pada BPJS Kesehatan agar memudahkan dalam melakukkan kegiatan dan informasi yang 
dibutuhkan. User yang terlibat yaitu peserta, channel pembayaran, bagian keuangan dan bagian pelayanan saperti pada gambar 4 .

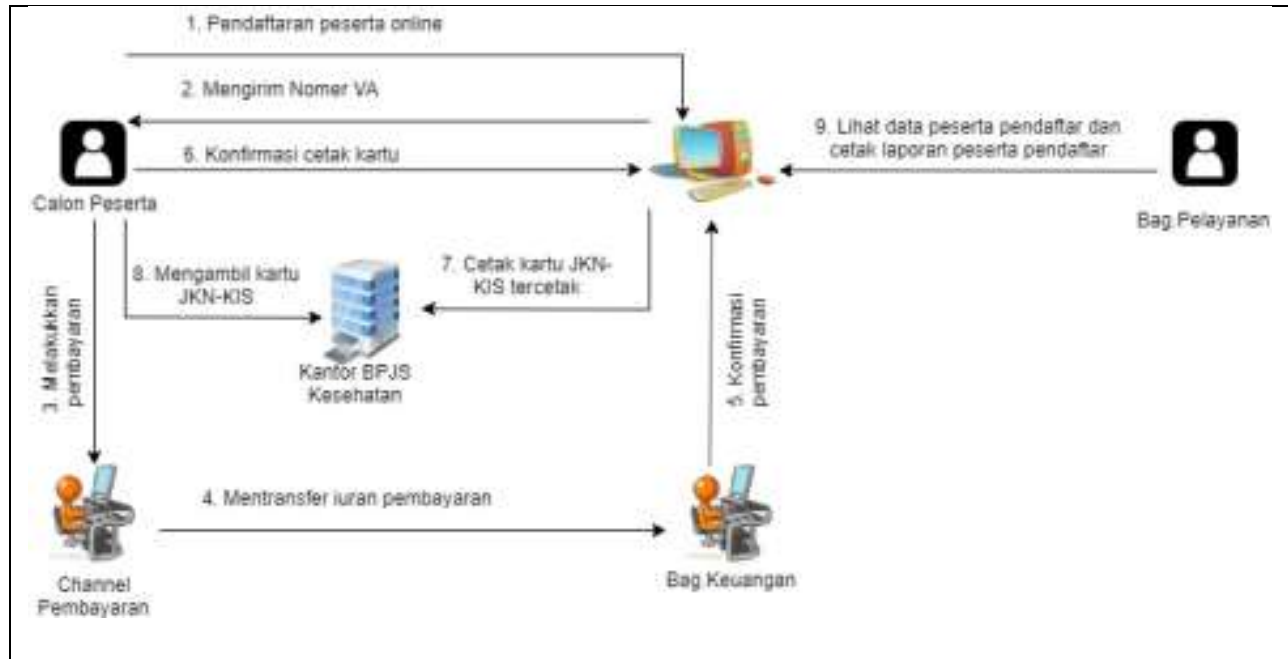

Gambar 4. Usulan Sistem Pendaftaran Calon Peserta BPJS Kesehatan

\subsection{Phase C : Information System Architecture}

Pada sistem yang berjalan saat ini pada BPJS Kesehatan belum memiliki data architecture. Untuk itu dalam pembuatan dan perancangan data akan digunakan Class Diagram agar mendukung proses bisnis BPJS Kesehatan Cabang Kendal yang tampak pada gambar 5.

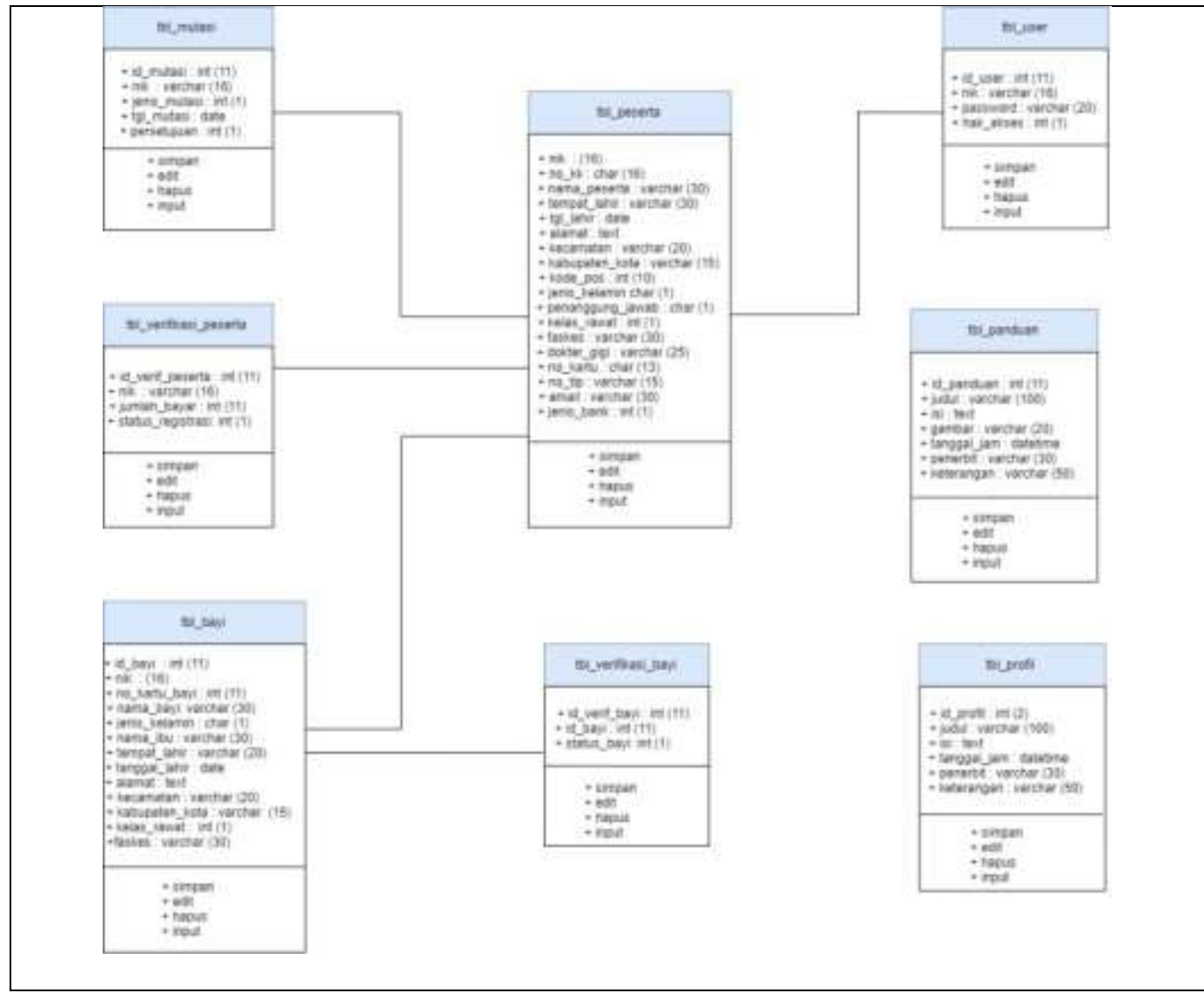

Gambar 5. Data Architecture Pada BPJS Kesehatan 


\subsection{Phase D : Teknologi Information}

Arsitektur teknologi menggambarkan dan menjelaskan adanya jaringan serta hardware dan software yang digunakan untuk mendukung pelayanan, informasi, arus data dan jalannya aplikasi yang menunjang kegiatan di BPJS Kesehatan. Dalam arsitektur teknologi akan dijelaskan infrastruktur jaringan saat ini dan usulan jaringan untuk BPJS Kesehatan serta konfigurasi hardware dan software yang doperlukan dalam infrastruktur jaringan yang tampak pada gambar 6.

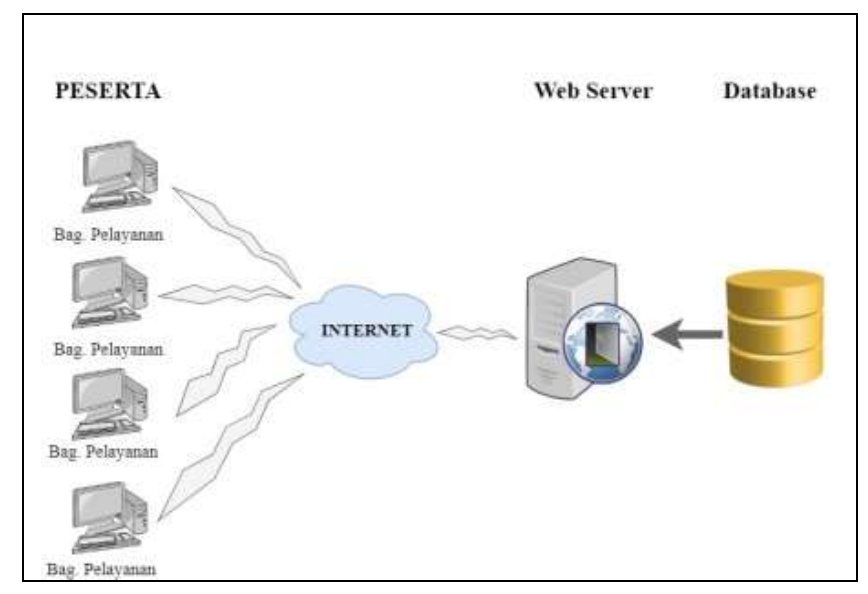

Gambar 6. Jaringan Teknologi Usulan

\subsection{Phase E : Opportunities and Solution}

1. Analisa GAP Architecture Teknologi

Dalam gambar 7 analisa gap arsitektur teknologi mengalami penambahan penggunaan

Web Server, Application Server, Switch dengan memberikan keterangan Add karena teknologi yang awalnya belum ada akan baru digunakan. Pada Web Browser, internet, wireless diberikan keterangan RT (retain) dimana teknologi tersebut sudah ada pada sistem sebelumnya dan masih dipergunakan pada sistem baru.

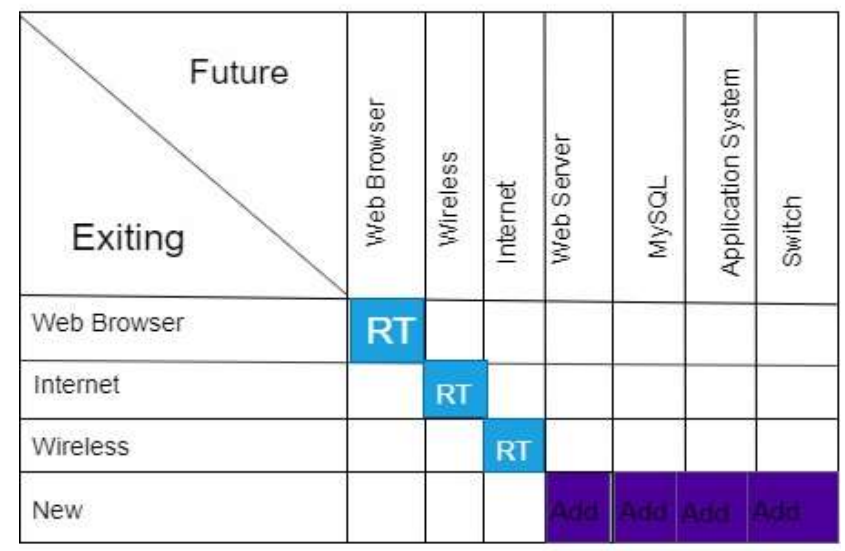

Gambar 7. Analisa GAP Architecture Teknologi

2. Analisa GAP Architecture Sistem Informasi

Analisa gap arsitektur aplikasi yang mempunyai penambahan sistem informasi pelayanan kepesertaan BPJS Kesehatan dan sistem informasi konfirmasi kepesertaan BPJS Kesehatan. Penambahan yang dilakukkan dengan mengembangkan sistem yang telah ada seperti sistem informasi pelayanan kepesertaan dan sistem informasi konfirmasi kepesertaan.Aplikasi Microsoft Exel 2010 yang diberi keterangan RP (replace) untuk cetak laporan aka diganti 
dengan sistem pelayanan kepesertaan yang ada dengan adanya penambahan fitur pada sistem pelayanan kepesertaan BPJS Kesehatan. Sistem keuangan BPJS Kesehatan dan JKN-Mobile diberi keterangan RT (retain) yang artinya masih tetap dipergunakan yang tampak pada gambar 8 .

\begin{tabular}{|c|c|c|c|c|c|}
\hline Future & 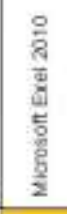 & 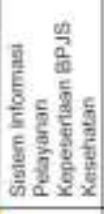 & 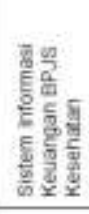 & 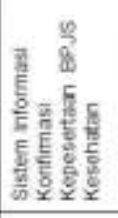 & $\begin{array}{l}\frac{g}{\frac{9}{8}} \\
\frac{2}{2} \\
\frac{2}{2}\end{array}$ \\
\hline Microson Exel 2010 & RP & & & & \\
\hline $\begin{array}{l}\text { Sistem intormasi } \\
\text { Pelayanan Kapesentaan } \\
\text { BPJS Keseriazan }\end{array}$ & & & & & \\
\hline $\begin{array}{l}\text { Sistem Informasi } \\
\text { Keuangan BPSS. } \\
\text { Kesenastan }\end{array}$ & & & RT & & \\
\hline $\begin{array}{l}\text { Sistem informasi } \\
\text { Konflmasi Kepesertaan } \\
\text { BPJS Keseharan }\end{array}$ & & & & & \\
\hline JKON Mobie & & & & & RT \\
\hline New & & & & & \\
\hline
\end{tabular}

Gambar 8. Analisa GAP sistem informasi

3. Analisa GAP Architecture Bisnis

Dalam gambar 9 analisa gap pada arsitektur bisnis yang mengalami penambahan yaitu dengan diberi keterangan Add yaitu Login. Karena sebelum memanfaatkan sistem informasi yang ada akan dibutuhkan Login untuk proses bisnis yang ada.

\begin{tabular}{|c|c|c|c|c|c|c|}
\hline Exiting & 孞 & 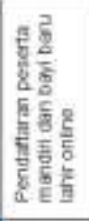 & 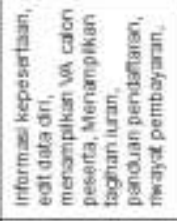 & 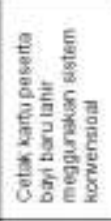 & 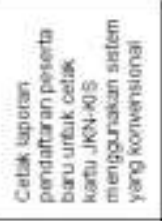 & 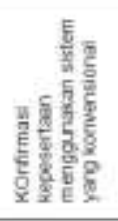 \\
\hline 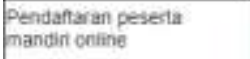 & RT & & & & & \\
\hline 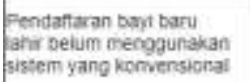 & & RP & & & & \\
\hline 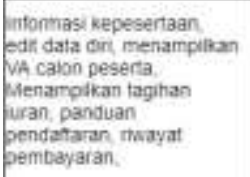 & & & RT & & & \\
\hline 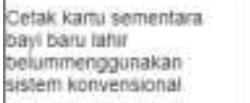 & & & & RP & & \\
\hline 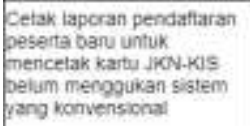 & & & & & RP & \\
\hline 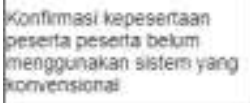 & & & & & & RP \\
\hline New & Add & & & & & \\
\hline
\end{tabular}

Gambar 9.Analisa GAP Architecture Bisnis 
Pendaftaran bayi baru lahir, cetak kartu sementara bayi baru lahir, cetak laporan pendaftaran peserta baru untuk mencetak kartu JKN-KIS dan konfirmasi kepesertaan bagi peserta yang akan mengajukan mutasi akan diberikan keterangan RP (replace) karena sistem tersebut tetap akan digunakan dalam sistem baru. Berbagi informasi kepada peserta, berbagi informasi pada stakeholder diberikan keterangan RT (retain) artinya masih tetap akan digunakan

\subsection{Phase F : Migration Planning}

Rencana migrasi sistem menggunakan 2 metode yaitu yang pertama konversi bertahap (phase in conversion) dengan cara menggantikan suatu bagian dari sistem pelayanan yang lama dengan yang baru seperti pada tabel 3, Jika terjadi sesuatu pada sistem pleyanan yang baru maka akan diganti kembali dengan yang lama. Metode yang kedua menggunakan konversi pilot (pilot conversion) yang dilakukkan dengan cara menerapkan sistem baru hanya bapada bagian lokasi tertentu terutama pada bagian pelayanan BPJS Kesehatan yang diperlukan sebagi pelopor.

\section{Tabel 3. Migration Planning}

\begin{tabular}{ll} 
No & \multicolumn{1}{c}{ Nama Aplikasi } \\
\hline 1. & Website BPJS Kesehatan \\
2. & Sistem Informasi Pelayanan Kepesertaan BPJS Kesehatan \\
3. & Sistem Informasi Keuangan BPJS Kesehatan \\
4. & Sistem Informasi Konfirmasi Peserta BPJS Kesehatan \\
\hline
\end{tabular}

\subsection{Phase G : Implementation Governance}

Pada tahapan ini menghasilkan suatu prototype dari berupa aplikasi system informasi pelayanan terhadap BPJS Kesehatan. Dan salah satu tampilan hasil implementasi tersebut ditunjukan pada gambar 10 dibawah ini.

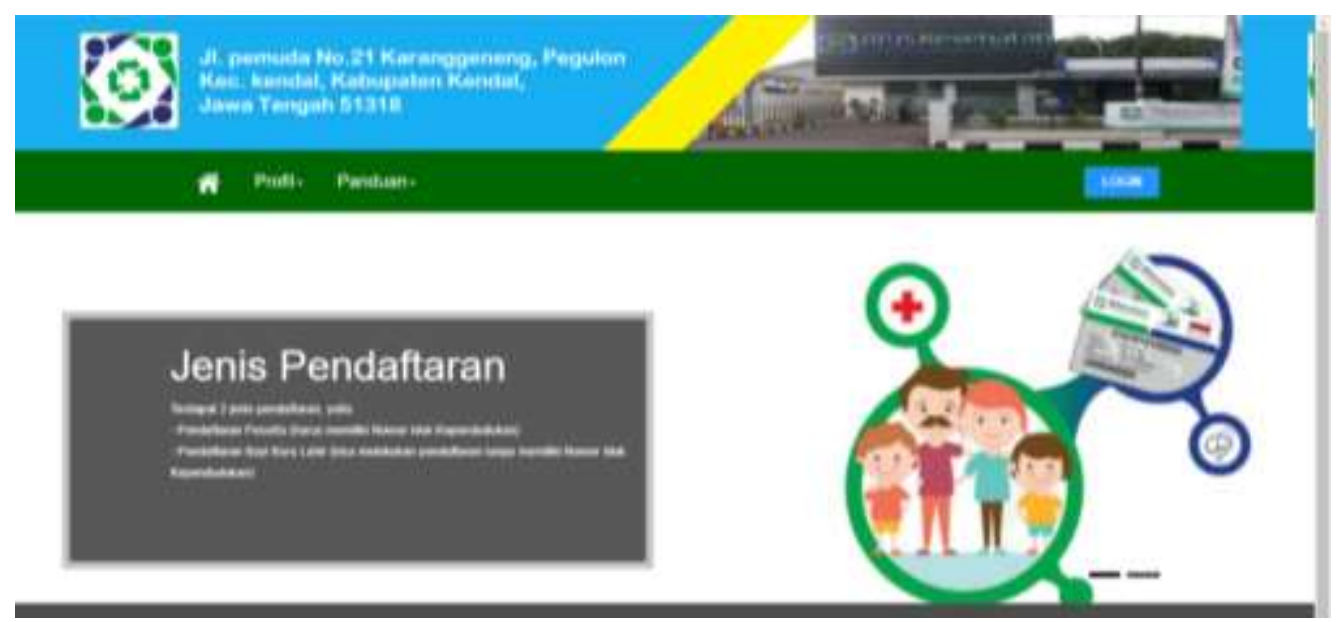

Gambar 10.Implementasi Sistem PelayananPhase H : Architecture Change Management

Perubahan yang ada pada suatu organisasi atau perusahaan tidak bisa memisahkan antara persoalan secara teknis yang terkait dengan teknologi informasi dengan persoalan non teknis seperti manajement perubahan. Change Management dilakukkan pada tiga tingkat yaitu personal, perubahan organisasi dan perubahan teknologi. Perubahan teknologi adalah pada proses pekerjaan, metode-metode dan perlengkapan organisasi untuk memenuhi kebutuhan Sistem Pelayanan BPJS Kesehatan maupun insfrastruktur pendukung Sistem Pelayanan BPJS Kesehatan Cabang Kendal. 


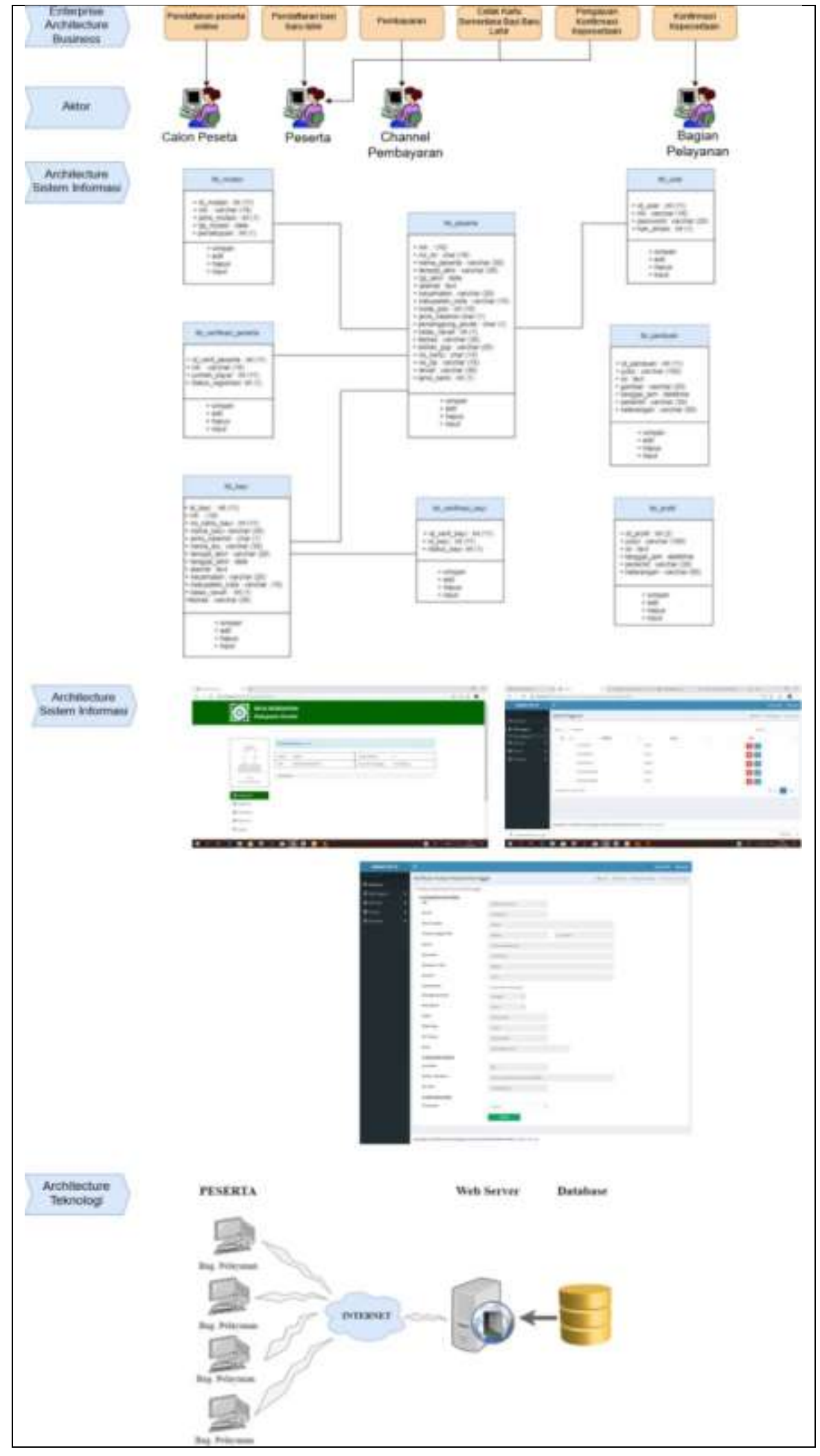

Gambar 12 Blueprint Sistem Pelayanan BPJS Kesehatan 


\section{KESIMPULAN}

Berdasarkan penelitian yang telah dilakukkan dalam tugas akhir ini, maka dapat diambil kesimpulan bahwa rancangan Sistem Informasi Pelayanan BPJS Kesehatan berbasis web dengan menggunakan framework TOGAF menghasilkan rancangan blueprint yang terdiri dari arsitektur bisnis, arsitektur sistem informasi dan arsitektur teknologi. Dengan adanya rancangan blueprint dapat menghasilkan prototype Sistem Pelayanan BPJS Kesehatan Cabang Kendal yang dapat mempermudah proses pendafataran peserta bayi baru lahir, proses konfirmasi kepesertaan yang belum ada mengakibatkan muncul tagihan secara terus menerus dan proses cetak kartu sementara bayi baru lahir.

\section{SARAN}

Diharapkan hasil blueprint dapat sebagai panduan dalam pengembangan Sistem Pelayanan BPJS Kesehatan pada Kantor Cabang Kendal. Pada penelitian selanjutnya, dengan topik yang sama dapat dikembangkan dengan menggunakan framework lainnya seperti Zachman, untuk membandingkan penelitian. Pada penelitian selanjutnya, dengan topic yang sama dapat dikembangkan dengan menambahkan kartu JKN-KIS digital dan pencarian faskes terdekat dengan menggunakan metode google maps api.

\section{DAFTAR PUSTAKA}

[1] Aprilia , A. A. (2018). Seminar Nasional Sistem Informasi Indonesia. Perencanaan Arsitektur Enterprise Menggunakan TOGAF ADM (Architecture Development Method) Pada Dinas Kesehatan Kota Salatiga.

[2] Widada, T. (2017). Peran Badan Penyelenggara Jaminan Sosial (BPJS) Kesehatan dan Implikasinya Terhadap Ketahanan Masyarakat (Studi di RSUD Hasanuddin Damrah Manna, Kabupaten Bengkulu Selatan, Provinsi Bengkulu). Jurnal Kesehatan Nasional, 199-216.

[3] Snati, L. (2015). Kajian Perkembangan Dan Usulan Perancangan Enterprise Architecture Framework. Perancangan, 17-18.

[4] Gunawan, M. N. (2017). Perencanaan Arsitektur Enterprise Dengan Metode TOGAF Versi 9 (Studi Kasus: RSUD. Kota Tangerang Selatan), Informasi, P-ISSN 1979-0767.

[5] Mikroskil.P.M. (2014). Penerapan Enterprise Architecture Framework Untuk Pemodelan. Vol.13, No.12, pp 159-168.

[6] O. G. Standard and T. O. Group, TOGAF ® Version 9.1. 2011 